\title{
Article
}

\section{The Lausanne Infant Crying Stress Paradigm: Validation of an Early Postpartum Stress Paradigm with Women at Low vs. High Risk of Childbirth-Related Posttraumatic Stress Disorder}

\author{
Vania Sandoz ${ }^{1}$, Suzannah Stuijfzand ${ }^{1}$, Alain Lacroix ${ }^{1}$, Camille Deforges ${ }^{1}$, Magali Quillet Diop ${ }^{1}$, \\ Ulrike Ehlert $^{2}$, Marius Rubo ${ }^{3}$, Nadine Messerli-Bürgy ${ }^{3,+}+$ (i) and Antje Horsch ${ }^{1,4, *,+}$ (i) \\ 1 Institute of Higher Education and Research in Healthcare (IUFRS), University of Lausanne, \\ 1010 Lausanne, Switzerland; Vania.Sandoz@bluewin.ch (V.S.); Suzannah.Stuijfzand@protonmail.com (S.S.); \\ Alain.Lacroix@chuv.ch (A.L.); Camille-Deforges@hotmail.fr (C.D.); Magali.QuilletDiop@gmail.com (M.Q.D.) \\ 2 Department of Clinical Psychology and Psychotherapy, University of Zurich, 8050 Zurich, Switzerland; \\ U.Ehlert@psychologie.uzh.ch \\ 3 Clinical Child Psychology \& Biological Psychology, University of Fribourg, 1701 Fribourg, Switzerland; \\ Marius.Rubo@unifr.ch (M.R.); Nadine.Messerli@unifr.ch (N.M.-B.) \\ 4 Neonatology Service, Department Woman-Mother-Child, Lausanne University Hospital and University of \\ Lausanne, 1011 Lausanne, Switzerland \\ check for \\ updates \\ * Correspondence: Antje.Horsch@chuv.ch; Tel.: +41-79-556-0750 \\ + Joint last authors.
}

Citation: Sandoz, V.; Stuijfzand, S.; Lacroix, A.; Deforges, C.; Quillet Diop, M.; Ehlert, U.; Rubo, M.; Messerli-Bürgy, N.; Horsch, A. The Lausanne Infant Crying Stress Paradigm: Validation of an Early Postpartum Stress Paradigm with Women at Low vs. High Risk of Childbirth-Related Posttraumatic Stress Disorder. J. Pers. Med. 2021, 11, 472. https://doi.org/10.3390/ jpm11060472

Academic Editors: Antonio Armario, Roser Nadal and Javier Labad

Received: 12 April 2021

Accepted: 24 May 2021

Published: 26 May 2021

Publisher's Note: MDPI stays neutral with regard to jurisdictional claims in published maps and institutional affiliations.

Copyright: (c) 2021 by the authors. Licensee MDPI, Basel, Switzerland. This article is an open access article distributed under the terms and conditions of the Creative Commons Attribution (CC BY) license (https:// creativecommons.org/licenses/by/ $4.0 /)$.

\begin{abstract}
Stress reactivity is typically investigated in laboratory settings, which is inadequate for mothers in maternity settings. This study aimed at validating the Lausanne Infant Crying Stress Paradigm (LICSP) as a new psychosocial stress paradigm eliciting psychophysiological stress reactivity in early postpartum mothers $(n=52)$ and to compare stress reactivity in women at low $(n=28)$ vs. high risk $(n=24)$ of childbirth-related posttraumatic stress disorder (CB-PTSD). Stress reactivity was assessed at pre-, peri-, and post-stress levels through salivary cortisol, heart rate variability (high-frequency (HF) power, low-frequency (LF) power, and LF/HF ratio), and perceived stress via a visual analog scale. Significant time effects were observed for all stress reactivity outcomes in the total sample (all $p<0.01$ ). When adjusting for perceived life threat for the infant during childbirth, high-risk mothers reported higher perceived stress $(p<0.001, d=0.91)$ and had lower salivary cortisol release $(p=0.023, d=0.53)$, lower LF/HF ratio $(p<0.001, d=0.93)$, and marginally higher HF power $(p=0.07, d=0.53)$ than low-risk women. In conclusion, the LICSP induces subjective stress and autonomic nervous system (ANS) reactivity in maternity settings. High-risk mothers showed higher perceived stress and altered ANS and hypothalamic-pituitary-adrenal reactivity when adjusting for infant life threat. Ultimately, the LICSP could stimulate (CB-)PTSD research.
\end{abstract}

Keywords: PTSD; cortisol; heart rate variability; stress reactivity; childbirth; TSST; postpartum; women; mothers; perceived stress

\section{Introduction \\ 1.1. Childbirth-Related Posttraumatic Stress Disorder}

Posttraumatic stress disorder (PTSD) may develop following a traumatic event, as defined by the PTSD stressor criterion of the Diagnostic and Statistical Manual of Mental Disorders, 5th ed. (DSM-5) [1]. Four symptom clusters (criteria B-E of the DSM-5) characterize this disorder: intrusions, avoidance of trauma-related cues, negative cognitions and mood, and hyperarousal [1]. PTSD can be diagnosed one month following the traumatic stressor [1], even if an acute posttraumatic stress response can be observed in the meantime [2]. The question arises to understand why after having been exposed to a traumatic event, only some individuals develop PTSD symptoms [3]. According to psychobiological 
findings, altered stress reactivity, such as a dysregulation of the hypothalamic-pituitaryadrenal (HPA) axis or the autonomic nervous system (ANS), may play a major role in the development of PTSD [4,5].

Up to one-third of mothers report perceiving giving birth as traumatic [6-8] and may develop childbirth-related PTSD (CB-PTSD) $[9,10]$. According to the DSM-5 PTSD stressor criterion, perceived life threat is a key element contributing to the traumatic appraisal of childbirth [1]. Therefore, mothers who fear for their life or physical integrity, or the life or physical integrity of their infant, during childbirth are at higher risk of CB-PTSD compared to those who do not $[1,11]$. In community samples, $3-4 \%$ of women reach the clinical threshold for CB-PTSD [12,13], whereas in high-risk samples, CB-PTSD prevalence rates increase up to $16-19 \%[12,13]$. Studies investigating the relationships between CBPTSD and traumatic childbirth experience and parity reported inconsistent results [14-17]. Although traumatic childbirth perception depends on the maternal subjective appraisal of the event, objective elements, such as obstetric or neonatal complications, can worsen the traumatic experience [11].

There are several arguments to assume that CB-PTSD might differ from PTSD by the nature of its trauma $[18,19]$. As a positive and expected life event, childbirth is generally perceived positively by society. Mothers might be terrified not only for themselves but also for their infant, which differs from other traumatic events. The perceived life threat for the infant is a strong predictor of CB-PTSD [17]. Accordingly, mechanisms involved in the development of CB-PTSD might be different from the ones of PTSD following other traumatic events.

Besides the maternal distress and interference with everyday functioning due to CBPTSD symptoms [9], CB-PTSD can negatively affect the couple relationship [20,21] and subsequent future reproductive experiences [22,23]. Maternal CB-PTSD symptoms may also be associated with child sleep problems [22,24], breastfeeding initiation and continuation $[22,25]$, and, potentially, with problems regarding the mother-infant relationship or bonding $[22,26]$.

To date, evidence-based interventions to prevent CB-PTSD are lacking [27]. Given the significant consequences of CB-PTSD on mothers and their families, it is fundamental to better understand the underlying physiological mechanisms that play a role in the development of CB-PTSD, as this may open up options for the early assessment and treatment of CB-PTSD [28].

\subsection{Psychophysiological Stress Reactivity and Posttraumatic Stress Disorder}

The stress response system is composed of the sympathetic (SNS) and the parasympathetic (PNS) branches of the ANS and the HPA axis [29]. Under stress conditions, HPA activation increases (elevation of cortisol release), whereas PNS activation withdraws (reduction in high-frequency (HF) power), and SNS activation intensifies (increase in lowfrequency (LF) power), resulting in a short-term imbalance of the ANS (assessed by LF/HF ratio) [29]. Cortisol release peaks at 10 to $30 \mathrm{~min}$ after stress exposure, whereas changes in SNS and PNS activation are seen more immediately [29]. Cortisol is released to mobilize physiological and psychological resources of the organism and to support recovery by counteracting the physiological effects of the SNS activation [29]. Cortisol release gradually increases during pregnancy, with a peak at the end of the pregnancy, and then returns to nongravid levels $12-24 \mathrm{~h}$ after childbirth [30-33]. There is evidence that early postpartum conditions can have an additional impact on cortisol release, such as breastfeeding within the last hour that causes blunted cortisol stress reactivity [34].

Overall, the literature suggests that the development and maintenance of PTSD are related to HPA dysregulation [35]. Individuals exposed to trauma or with PTSD show mainly blunted stress responses [35-38], and only one study with childhood abuse-related PTSD in women showed elevated salivary cortisol responses following exposure to traumatic reminders compared to women with a history of childhood abuse but without PTSD [39]. However, given the small sample size ( $n=12$ per group) and the unstandardized stress 
procedure, the interpretation of these findings requires caution. All other studies reported blunted cortisol reactivity in response to laboratory stress induction (e.g., Trier Social Stress Test (TSST), Emotional Stroop task), including a study on US female veterans compared to civilian women, regardless of their PTSD status [38], or in postpartum women with emotion regulation difficulties and a history of child maltreatment [37]. Similar results were found in mothers suffering from interpersonal violence-related PTSD at 12 and 48 months postpartum [40].

PTSD patients had altered ANS responses at rest compared to controls in a metaanalysis (i.e., reduced HF and LF power, with a higher reduction in HF than LF, and increased LF/HF ratio), indicating that the cardiovascular system cannot properly adapt to external and internal demands [5]. Further, in response to lab-based stress tasks, individuals showed an increase in SNS, a decrease in PNS activation, and a short-term imbalance of the ANS [41-43]. As far as we know, there is no study that investigated early postpartum mothers with a traumatic childbirth experience who might be at risk of CB-PTSD, even though hormonal changes linked to childbirth might influence ANS and HPA activation. It furthermore remains unclear whether the physiological changes can already be expected early after trauma at a time point where PTSD is not yet established. In addition, stress also provokes a psychological stress response, such as perceived stress [44,45]. To our knowledge, no study has yet investigated early perceived stress reactivity in women following traumatic childbirth or in individuals at risk of CB-PTSD.

\subsection{The Current Study}

Assessment of stress responses during the early postpartum period is limited due to the physical and psychological constraints of the early postpartum period in women (e.g., standing up during the stress phase can be physically impossible, and pretending to be in a job interview, as it is used in standard lab-based stress tasks, is likely to be far from maternal concerns during the days following childbirth) [46-48]. Nevertheless, studying psychophysiological stress reactivity in mothers during the early postpartum period could be relevant to identify CB-PTSD risk factors and to clarify physiological mechanisms underlying the development of CB-PTSD [35].

Therefore, the current study firstly aimed to provide the first evidence for the validation of a new stress paradigm, the Lausanne Infant Crying Stress Paradigm (LICSP), for the early postpartum period. More specifically, we hypothesized a psychophysiological stress response to the LICSP (i.e., increase in salivary cortisol release, reduction in HF power, increase in LF power, increase in LF/HF ratio, and increase in perceived stress).

Given that the general PTSD literature reported altered physiological stress reactivity in traumatized individuals, this study secondly intended to investigate group differences in psychophysiological stress reactivity in women at low vs. high risk of CB-PTSD in the early days following childbirth. However, given that stress reactivity has never been studied shortly after the traumatic stress exposure, exploratory analyses were conducted for group differences.

\section{Materials and Methods}

\subsection{Design and Study Population}

This cross-sectional experimental study took place in the postpartum ward of the maternity unit of a Swiss university hospital between December 2018 and December 2019. The following inclusion criteria were applied: (a) being $\geq 18$ years old, (b) having given birth to a live baby at $\geq 34$ weeks of gestation during the previous $\leq 5$ days, (c) having given written consent, and (d) obtaining a certain score in response to screening questions that allowed the allocation to the groups at low vs. high risk of CB-PTSD. For this purpose, willing mothers answered screening questions consisting of two items related to perceived life threat during childbirth (based on PTSD stressor criteria of DSM-5) $[1,18,48]$. Responses were scored on a 7-point Likert scale $(1=$ not at all to $7=$ extremely): "Did you think that your life was in danger?" "Did you think that your baby's life was in danger?" To be 
included in the study, low-risk participants had to respond $\leq 2$ to each of the two items, whereas high-risk participants had to score $\geq 4$ on one of the two items. The reason for such classification was to ensure participants were either not traumatized or sufficiently traumatized to find group differences. Exclusion criteria included (a) insufficient French language skills, (b) established intellectual disability or psychotic illness, (c) antenatal corticosteroid administration, (d) current alcohol abuse and/or illegal drug use, (e) severe maternal and/or infant illness, and (f) infant hospitalized in neonatal intensive care unit. The total sample consisted of 52 participants, with 28 mothers in the low-risk group and 24 in the high-risk group.

As part of the Swiss Traumatic Birth Trial (START) [18], this study was conducted in accordance with the Declaration of Helsinki and was approved by the local ethics committee for research in humans (study number 2017-02142). Before enrolling in the current study, participants received an information sheet and gave written consent. The current study was written up according to the STROBE reporting statements [49].

\subsection{Procedure and Measures}

\subsubsection{The Lausanne Infant Crying Paradigm Procedure}

The LICSP development was based on the principal components of the TSST, which is the gold standard paradigm to induce physiological stress responses in adults [46-48]. The LICSP procedure comprised a baseline phase, a stress phase, and a recovery phase, ending with an $8 \mathrm{~min}$ optional guided relaxation. Both the baseline and the recovery phases lasted $40 \mathrm{~min}$, whereas the stress phase lasted $20 \mathrm{~min}$.

Mothers were encouraged to breastfeed and were asked to have lunch before starting the LICSP at 1 p.m. Visitors were prohibited during the whole LICSP procedure, which coincided with the time the maternity did not allow other visitors than partners (outside of public visiting hours). During the baseline and the recovery phases, participants were instructed to rest in their hospital bed with their baby around and their partner (if they were present). During the stress phase, participants were alone in a separate consultation room sitting at a desk and facing an unknown female experimenter that observed them, gave them instructions, and adopted a neutral facial attitude [47]. All participants were filmed on the pretext that their facial expressions and their stress coping skills would be analyzed by specialists. The stress phase consisted of a 3 min anticipation of the infant crying test (ICT), the ICT being a psychosocial stressor, and a surprise mental arithmetic task as a cognitive stressor [47]. The ICT involved differentiating one's own infant crying among several recordings of infant crying. The experimenter read instructions implying that mothers usually differentiate their infant's crying from those of others, which can threaten the social self of participants and induce stress [46,50]. Actually, mothers can recognize their own infant crying already at $24 \mathrm{~h}$ postpartum, but they cannot differentiate it from the crying of other infants [51]. The instructions of the surprise mental arithmetic task did not differ from the ones used in the TSST [47].

The ICT was designed and run with E-Prime 3.0 software (Psychology Software Tools, Pittsburgh, PA, USA). Five $20 \mathrm{~s}$ recordings of infant crying were first played to participants through headphones, followed by 14 other $10 \mathrm{~s}$ infant crying recordings. Between each infant crying recording, participants had $3 \mathrm{~s}$ to indicate by pressing on specific keyboard keys whether this was their own infant crying or not. Among the 19 infant crying clips, one of $10 \mathrm{~s}$ length and another of $20 \mathrm{~s}$ were from the participant's own infant. Those two crying clips were recorded prior to the LICSP during a routine care episode (e.g., diaper change, bath) in the absence of the participant.

Both the psychosocial and cognitive stressors contained the main evidence-based characteristics required to elicit psychosocial stress: anticipation, novelty and/or unpredictability, social-evaluative threat, uncontrollability, and motivated performances $[45,46,52]$. Figure 1 illustrates the LICSP procedure, including time points of measurements. At the end of the recovery phase, a guided relaxation was offered to participants, followed by a moment to debrief to ensure no side effects would result from the stress phase. Finally, 
participants completed a set of questionnaires (see Section 2.2.3) right after the LICSP or during their stay in the postpartum ward.

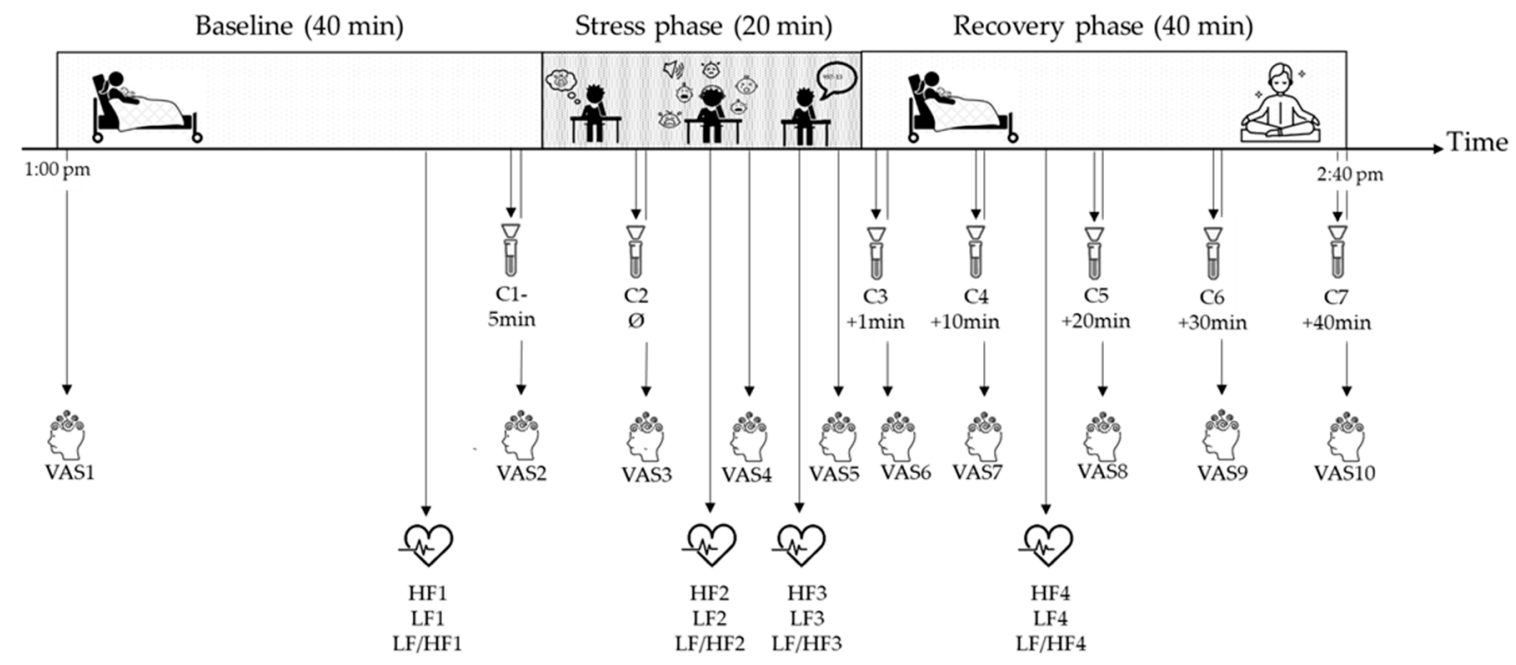

Figure 1. The procedure of the Lausanne Infant Crying Stress Paradigm contains a baseline phase and recovery phase, in which participants rest in their hospital room with their baby, as well as a stress phase, in which participants complete three stressful tasks (i.e., $3 \mathrm{~min}$ anticipation of the infant crying test, the infant crying test, and a surprise mental arithmetic task) in a consultation room. At the end of the recovery phase, an optional guided relaxation is offered to participants. Salivary cortisol assessments are represented by salivette icons, with the 1st salivary sample (C1) taken 5 min before the beginning of the stress phase, the 2nd salivary sample (C2) taken after the $3 \mathrm{~min}$ anticipation before the psychosocial and cognitive stressors, and the 3rd to 7th salivary samples (C3-C7) taken after the stress phase at 10 min interval. Perceived stress is illustrated with the head icon, measured 10 times via a visual analog scale (VAS) ranging from $1=$ not at all stressed to 5 = extremely stressed. Heart rate variability covering high-frequency (HF) power, low-frequency (LF) power, and LF/HF ratio is symbolized by the heart icon and is measured at four different time points.

\subsubsection{Psychophysiological Stress Responses}

Given that saliva collection does not induce additional stress and is noninvasive and reliable, salivary cortisol was chosen as a measure of the HPA activity in response to stress [52,53]. As illustrated in Figure 1, saliva was obtained using Salivettes (Sarstedt, Sevelen, Germany) $5 \mathrm{~min}$ before the start of the stress phase (C1) and directly after the $3 \mathrm{~min}$ anticipation of the ICT (C2). Five additional samples were collected during the recovery phase at 10 min intervals (after the stressor; during early, mid, and late recovery; and at the end of the paradigm (C3 to $\mathrm{C} 7)$ ). The timing of salivary collection is consistent with the standardized protocol of the TSST, with a salivary cortisol peak response expected between 10 and 30 min post-stress (i.e., C4 to C6) [29,47]. Participants were instructed not to eat, drink, chew gum, or brush teeth within $30 \mathrm{~min}$ before saliva collection. After chewing the cotton wool for $60 \mathrm{~s}$, salivary samples were stored at $\leq 20^{\circ} \mathrm{C}$ until they were sent for analysis to the biochemical laboratory of the Clinical Psychology and Psychotherapy Department at the University of Zurich, Switzerland. Cortisol levels (nmol/L) were analyzed using luminescence immunoassay based on the competition principle (IBL, Hamburg, Germany). Inter- and intra-assay coefficients of variance of cortisol were $\leq 5 \%$.

Cardiac activity was measured continuously via a Firstbeat Bodyguard 2 (Firstbeat Technologies Ltd., Jyväskylä, Finland) ECG device. During the 3 min recordings of the baseline (i.e., HF1, LF1, and LF/HF1) and recovery (i.e., HF4, LF4, and LF/HF4) phases, participants were instructed to rest in their hospital beds and were allowed to be with their baby. The Kubios HRV Standard software (ver. 3.2.0) was used to graphically display the cardiac activity in order to spot outliers. Data quality was assessed by inspecting the normality of interbeat intervals (IBI values) for each recording and by comparing HRV metrics with and without the Kubios' artifact correction algorithm applied (set to 
medium). Data quality was high in all recordings; therefore, no artifact correction was necessary. Frequency-domain HRV parameters (i.e., HF power, LF power, and LF/HF ratio) were calculated using fast Fourier transformation. LF power (range: $0.04-0.15 \mathrm{~Hz}$ ) reflects mainly SNS activation, whereas the HF power (range: $0.15-0.4 \mathrm{~Hz}$ ) echoes the PNS activation $[41,43]$. The LF/HF ratio illustrates the balance of SNS and PNS activity $[41,43]$.

Perceived stress was measured 10 times via a visual analog scale (VAS) rating from $1=$ not at all stressed to $5=$ extremely stressed (Figure 1) [54]. Perceived stress was assessed at the beginning and the end of the baseline phase, during the stress phase, at the end of the anticipation period and of the psychosocial and cognitive stressors, and, finally, during recovery at each time point of saliva sampling.

\subsubsection{Psychosocial and Medical Information}

Perceived life threat for the mother and the infant during childbirth was measured via the screening questions (see Section 2.1). To situate the sample and given that depression is frequent and comorbid with acute stress during the early postpartum period [55], depression was assessed via the Edinburgh Postnatal Depression Scale (EPDS) [56]. This self-report questionnaire assesses the severity of postnatal depression symptoms over the past week [56]. A sentence was added to instructions stating that researchers were particularly interested in how mothers feel since childbirth. The 10 items are scored on a 4-point Likert scale (0-3), with a total score ranging from 0 to 30 [56]. A higher score suggests a higher level of symptom severity [56]. The French version has demonstrated satisfying psychometric proprieties [57]. The internal consistency observed in the present study was good (Cronbach's $\alpha=0.85$ ) and was slightly higher than that previously reported in postpartum mothers of Switzerland [58,59].

Since anxiety is also common in the early postpartum period and comorbid with acute stress [55], anxiety was measured through the anxiety subscale of the Hospital Anxiety and Depression Scale (HADS-A). This 7-item self-report questionnaire retrospectively measures the severity of anxiety symptoms within the week preceding childbirth, using a 4-point Likert (0-3) scale that ranges from 0 to 21 [60]. Higher scores indicate greater symptom severity [60]. The French version has shown good psychometric characteristics [61] with Cronbach's alpha of 0.72, which is similar to previous studies of Swiss postpartum women [55,62].

Participants responded to psycho-sociodemographic questions on age, civil status, education level, and smoking habits. Parity, gravidity, and type of delivery were retrieved from medical records. In addition, a dichotomous variable was created depending on whether the participant breastfed over the $60 \mathrm{~min}$ preceding the stress phase (yes $=1, n o=2$ ).

\subsection{Evaluation of the Stress Phase of the Lausanne Infant Crying Stress Paradigm}

After the LICSP and as a manipulation check, participants were asked to evaluate the stress phase with a 100-point Likert scale $(0=$ not at all, $50=$ moderately, $100=$ extremely $)$ according to the following parameters: novelty, difficulty, stress, controllability, and predictability $[46,63]$.

\subsection{Sample Size Calculation}

Given that the LICSP is a new stress paradigm, no prior data existed for an a priori power calculation. Therefore, a sample size of $N=40$ was estimated based on previous studies using the TSST (i.e., the gold standard stress paradigm) [37,46,64]. The current study consequently aimed to include 50 mothers completing the LICSP procedure to account for a potential lower effect of the LICSP.

\subsection{Data Analysis}

All the statistical analyses were carried out using R v3.6.1 (running under RStudio v1.1.463) [64]. The salivary cortisol levels of two participants were missing for $\mathrm{C} 1$, and the 
perceived stress ratings of one participant were missing for the last assessment (VAS10). Given that these missing data represented $<30 \%$ of the dataset, they were imputed using Bayesian linear regression (NORM) for numerical values. The missing data imputation was performed by the mice package v3.11.0 algorithms [65]. Due to technical issues, the cardiac activity of one participant during the stress phase was missing. Given that more than $30 \%$ of her data were missing, these data were not imputed. Further, seven participants did not entirely perform the mental arithmetic task, but HRV data were not imputed.

Results were considered significant at $p<0.05$. Descriptive differences between the low- and high-risk groups were assessed with the appropriate statistical tests, namely the chi-square test $\left(X^{2}\right)$, the Fischer's exact test $(p)$, or the Mann-Whitney test $(W)$. Given that data did not meet assumptions for a two-way repeated-measures analysis of variance (ANOVA; group*time), the aligned ranks transformation repeated-measures ANOVA (ART ANOVA; group*time), i.e., a nonparametric test, was carried out. To assess stress reactivity to the LICSP, pairwise comparisons with Tukey adjustments were conducted as post hoc tests to determine differences between relevant pair groups. Effect sizes (Cohen's d) were calculated. Finally, one-way analyses of covariance (ANCOVAs) were conducted to determine differences between low- and high-risk groups in psychophysiological stress responses, using perceived life threat for the infant as a covariate. Results are reported as unadjusted and adjusted for perceived life threat for the infant. Given the potential impact of breastfeeding on salivary cortisol activity, an additional exploratory ANCOVA was carried out for this outcome. Note that, given the inconsistent literature on CB-PTSD or traumatic childbirth experience and parity, parity was not considered as a covariate in the current paper [14-17]. Finally, cortisol levels were expected to be low at $C 1$ and C2. However, as shown in Table 1, participants showed elevated cortisol release at C1. Therefore, $\mathrm{C} 2$ was considered as a baseline value for all the statistical analyses.

Table 1. Descriptive characteristics of the psychophysiological stress assessments.

\begin{tabular}{|c|c|c|c|}
\hline & Total Sample $(n=52)$ & Low-Risk Group $(n=28)$ & High-Risk Group ( $n=24)$ \\
\hline & $M S D$ & $M S D$ & $M S D$ \\
\hline \multicolumn{4}{|c|}{ Salivary cortisol (nmol/L) } \\
\hline C1 level & $5.5(2.57)$ & $5.31(2.57)$ & $5.72(2.6)$ \\
\hline C2 level & $4.96(2.19)$ & $4.87(2.27)$ & $5.06(2.15)$ \\
\hline C3 level ${ }^{1}$ & $4.98(2.13)$ & $5.03(2.31)$ & $4.92(1.96)$ \\
\hline C4 level ${ }^{1}$ & $5.07(2.35)$ & $5.26(2.79)$ & $4.86(1.79)$ \\
\hline C5 level ${ }^{1}$ & $5.12(2.47)$ & $5.13(2.8)$ & $5.12(2.12)$ \\
\hline C6 level ${ }^{1}$ & $4.7(2.13)$ & $4.79(2.29)$ & $4.61(1.98)$ \\
\hline C7 level ${ }^{1}$ & $4.51(2.19)$ & $4.65(2.51)$ & $4.35(1.82)$ \\
\hline \multicolumn{4}{|c|}{ HF power $\left(\mathrm{ms}^{2}\right)$} \\
\hline HF1 & $359.56(472.95)$ & 409.07 (593.5) & $301.79(275.74)$ \\
\hline $\mathrm{HF}^{2}{ }^{2}$ & $386.04(364.14)$ & $371.93(363.87)$ & $401.92(371.61)$ \\
\hline HF3 23 & $454.3(417.7)$ & $413.04(421.67)$ & $499.48(418.85)$ \\
\hline $\mathrm{HF} 4^{1}$ & 369.2 (427.57) & $416.19(508.43)$ & $318.29(321.41)$ \\
\hline \multicolumn{4}{|c|}{ LF power $\left(\mathrm{ms}^{2}\right)$} \\
\hline LF1 & $646.08(572.69)$ & $609.82(574.26)$ & $688.38(580.22)$ \\
\hline $\mathrm{LF}^{2}{ }^{2}$ & $497.08(440.61)$ & $410.44(280.52)$ & $594.54(560.67)$ \\
\hline LF3 23 & $1299.73(1101.02)$ & $1372.04(1336.12)$ & $1220.52(793.71)$ \\
\hline $\mathrm{LF}^{1}{ }^{1}$ & $663.36(483.53)$ & $602.81(491.58)$ & $728.96(476.23)$ \\
\hline \multicolumn{4}{|l|}{ LF/HF ratio } \\
\hline LF/HF1 & $2.95(2.22)$ & $2.67(1.81)$ & $3.27(2.62)$ \\
\hline $\mathrm{LF} / \mathrm{HF} 2^{2}$ & $2.17(3.09)$ & $2.26(3.96)$ & $2.06(1.72)$ \\
\hline $\mathrm{LF} / \mathrm{HF}^{23}$ & $3.74(2.79)$ & $4.39(3.18)$ & $3.03(2.13)$ \\
\hline $\mathrm{LF} / \mathrm{HF} 4^{1}$ & $2.71(1.78)$ & $2.38(1.53)$ & 3.07 (1.98) \\
\hline
\end{tabular}


Table 1. Cont.

\begin{tabular}{|c|c|c|c|}
\hline & Total Sample $(n=52)$ & Low-Risk Group $(n=28)$ & High-Risk Group ( $n=24)$ \\
\hline & $M S D$ & $M S D$ & $M S D$ \\
\hline \multicolumn{4}{|c|}{ Perceived stress } \\
\hline VAS1 & $1.67(0.83)$ & $1.54(0.79)$ & $1.83(0.87)$ \\
\hline VAS2 & $1.54(0.67)$ & $1.5(0.64)$ & $1.58(0.72)$ \\
\hline VAS3 & $2.43(0.96)$ & $2.25(0.7)$ & $2.65(1.18)$ \\
\hline VAS4 & $2.85(1.19)$ & $2.89(1.17)$ & $2.79(1.25)$ \\
\hline VAS5 $^{1}$ & $3.38(1.29)$ & $3.38(1.24)$ & $3.38(1.38)$ \\
\hline VAS6 $6^{1}$ & $2.24(1.19)$ & $1.96(1.04)$ & $2.54(1.28)$ \\
\hline VAS7 $^{1}$ & $1.68(0.87)$ & $1.5(0.81)$ & $1.88(0.9)$ \\
\hline VAS8 ${ }^{1}$ & $1.56(0.73)$ & $1.38(0.57)$ & $1.75(0.85)$ \\
\hline VAS9 $^{1}$ & $1.46(0.71)$ & $1.23(0.51)$ & $1.71(0.81)$ \\
\hline VAS10 ${ }^{1}$ & $1.27(0.53)$ & $1.15(0.46)$ & $1.39(0.57)$ \\
\hline
\end{tabular}

Note. $\mathrm{C} 1=1$ st salivary cortisol sample during the baseline; $\mathrm{C} 2=2$ nd salivary cortisol sample taken before the psychosocial and cognitive stressors; $\mathrm{C} 3=3$ rd salivary cortisol sample during recovery after the stress task; $\mathrm{C} 4=4$ th salivary cortisol sample during early recovery; C5 $=5$ th salivary cortisol sample during mid recovery; C6 $=$ 6th salivary cortisol sample during late recovery; C7 = 7th salivary cortisol sample during the recovery at the end of the paradigm; HF = high-frequency power; HF1 = HF during baseline; HF2 = HF during the psychosocial stressor; HF3 = HF during the cognitive stressor; HF4 = HF during the recovery; LF = low-frequency power; LF1 = LF during baseline; LF2 = LF during the psychosocial stressor; LF3 = LF during the cognitive stressor; LF4 = LF during the recovery; LF $/ \mathrm{HF} 1=\mathrm{LF} / \mathrm{HF}$ ratio during baseline; $\mathrm{LF} / \mathrm{HF} 2=\mathrm{LF} / \mathrm{HF}$ ratio during the psychosocial stressor; $\mathrm{LF} / \mathrm{HF} 3=\mathrm{LF} / \mathrm{HF}$ ratio during the cognitive stressor; $\mathrm{LF} / \mathrm{HF} 4=\mathrm{LF} / \mathrm{HF}$ ratio during the recovery; VAS $=$ visual analog scale ranging from $1=$ not all stressed to $5=$ extremely stressed; VAS1 $=$ perceived stress at the beginning of the LICSP; VAS2 $=$ perceived stress at C1; VAS3 $=$ perceived stress at C2; VAS4 = perceived stress at the end of the ICT; VAS5 = perceived stress at the end of the arithmetic task; VAS6 = perceived stress at C3; VAS7 = perceived stress at C4; VAS8 = perceived stress at C5; VAS9 = perceived stress at C6; VAS10 = perceived stress at C7. See Figure 1 for the detailed study procedure. ${ }^{1}$ Two participants of the low-risk group dropped at the end of the stress phase, resulting in two missing data points. ${ }^{2}$ Due to technical issues, the cardiac activity of one participant of the low-risk group was not recorded. Given $>30 \%$ of her data were missing, these data were not imputed. ${ }^{3}$ Seven participants $\left(n_{\text {low-risk }}=4, n_{\text {high-risk }}=3\right)$ decided to stop the surprise arithmetic task before the recording of the 3 min cardiac activity.

\section{Results}

\subsection{Characteristics of the Sample and of the Lausanne Infant Crying Stress Paradigm}

The study was presented to $n=195$ mothers, of whom $n=72$ agreed to answer the screening questions. The main reasons for declining participation were being tired, imminent return home, or being unavailable at the time of the LICSP. Of those who participated in the screening process, $n=20$ had a screening score that did not allow their group allocation; i.e., the perceived life threat of these women was not sufficiently low or high for them to continue with the study. The final study sample included $n=24$ mothers at high risk of CB-PTSD and $n=28$ CB-PTSD low-risk mothers. Two participants from the low-risk condition stopped the experiment after the stress phase and did not complete the recovery period.

Sociodemographic, medical, and psychological characteristics of the sample are presented in Table 2. The high-risk group reported a greater perceived life threat for the mother $(p=0.002)$ and for the infant $(p<0.001)$. The low- and high-risk groups significantly differed in the type of delivery, with more vaginal births and planned cesarian sections for the former and more operative vaginal births and emergency cesarian sections for the latter $(p<0.001)$. Further, low-risk mothers had a significant higher parity $(p=0.022)$ and gravidity $(p=0.013$ ) than high-risk mothers. As illustrated in Table 3, no significant group difference was observed regarding procedural characteristics of the LICSP. On average, the baseline phase lasted $44 \mathrm{~min}(S D=3 \mathrm{~min})$, the stress phase lasted $22 \mathrm{~min}(S D=3 \mathrm{~min})$, and the recovery phase lasted $43 \mathrm{~min}(S D=4 \mathrm{~min})$. 
Table 2. Descriptive data of the sample.

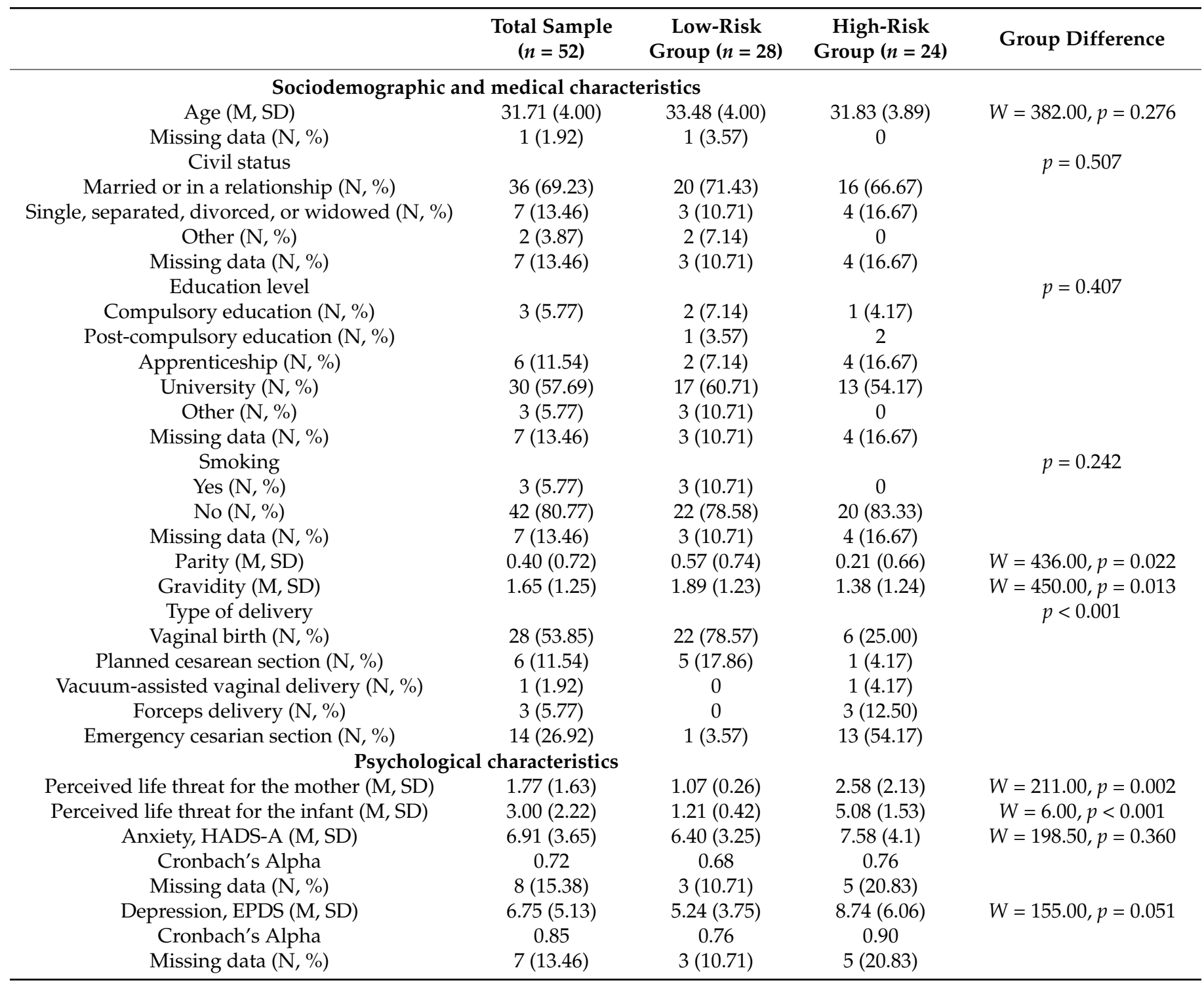

Note. HADS-A = anxiety subscale of the Hospital Anxiety and Depression Scale (range = 0-21); EPDS = Edinburgh Postnatal Depression Scale (range $=0-30)$. Significant group differences were tested with Fischer's exact test $(p)$ or Mann-Whitney test (W).

\subsection{Salivary Cortisol Response to Psychosocial Stress}

Table 3 shows the characteristics of the salivary cortisol assessments during the LICSP. Analyses revealed a significant time effect $(F(5,250)=4.84, p<0.001)$ for salivary cortisol (Figure 2). Salivary cortisol increase between C2 (baseline) and C4 (expected peak response within early recovery period, 10 min post-stress) was not significant $(p=0.94, d=0.01)$, but a significant difference was observed between baseline (C2) and recovery period $C 7$ (end of paradigm, $p=0.027, d=-0.21)$ and within recovery at C5 (20 min post-stress) and C7 (end of paradigm; $p=0.003 ; d=-0.27$ ), revealing that cortisol was high at baseline, kept the same level up to the expected peak time point, and was reduced afterward. There was a significant and moderate group effect when controlling for the perceived life threat for the infant $(F(1,309)=5.20, p=0.023, d=0.53)$, with mothers of the high-risk condition showing slightly lower adjusted mean level of salivary cortisol $(\mathrm{M}=4.26, \mathrm{SD}=1.96)$ than the ones of the low-risk group $(\mathrm{M}=5.44, \mathrm{SD}=2.40)$. Further, an exploratory ANCOVA examining the role of breastfeeding showed no significant group effect on salivary cortisol levels. 
Table 3. Descriptive data of the Lausanne Infant Crying Stress Paradigm.

\begin{tabular}{|c|c|c|c|c|}
\hline & $\begin{array}{l}\text { Total Sample } \\
\quad(n=52)\end{array}$ & $\begin{array}{c}\text { Low-Risk } \\
\text { Group }(n=28)\end{array}$ & $\begin{array}{c}\text { High-Risk } \\
\text { Group }(n=24)\end{array}$ & Group Differences \\
\hline $\begin{array}{l}\text { Time between birth and the LICSP (hh:mm) } \\
\qquad(\mathrm{M}, \mathrm{SD})\end{array}$ & $51: 04(22: 02)$ & $46: 23(21: 50)$ & $56: 31(21: 27)$ & $W=236, p=0.068$ \\
\hline LICSP start time (hh:mm p.m.) (M, SD) & $1: 13(0: 20)$ & $1: 13(0: 20)$ & $1: 15(0: 20)$ & $W=309.5, p=0.632$ \\
\hline Baseline phase duration (mm:ss) (M, SD) & $43: 43(3: 28)$ & $42: 58(2: 45)$ & $44: 35(4: 01)$ & $W=256.5, p=0.146$ \\
\hline Stress phase duration (mm:ss) (M, SD) & 21:41 (2:39) & $21: 58(3: 00)$ & $21: 23(2: 01)$ & $W=349, p=643$ \\
\hline Missing data $(\mathrm{N}, \%)$ & $1(1.92)$ & $1(3.57)$ & 0 & \\
\hline Recovery phase duration (mm:ss) (M, SD) & $42: 37(4: 28)$ & $43: 10(5: 53)$ & 42:02 (2:02) & $W=341.5, p=0.561$ \\
\hline Missing data $(\mathrm{N}, \%)$ & $2(3.85)$ & $2(7.14)$ & 0 & \\
\hline LICSP duration (mm:ss) (M, SD) & $107.68(4.61)$ & $107.38(4.73)$ & $108(4.56)$ & $W=289.5, p=0.668$ \\
\hline Missing data $(\mathrm{N}, \%)$ & $2(3.85)$ & $2(7.14)$ & 0 & \\
\hline $\begin{array}{c}\text { Breastfeeding within the hour preceding the } \\
\text { stress phase }\end{array}$ & & & & $X^{2}(1)=0.06, p=0.799$ \\
\hline Yes $(\mathrm{N}, \%)$ & $9(17.31)$ & $4(14.29)$ & $5(20.83)$ & \\
\hline No $(\mathrm{N}, \%)$ & $43(82.69)$ & $24(85.71)$ & $19(79.17)$ & \\
\hline \multicolumn{5}{|c|}{ Characteristics of the stress phase } \\
\hline Novelty (M, SD) & $77.80(28.34)$ & $72.12(29.91)$ & $83.96(25.75)$ & $W=220.5, p=0.061$ \\
\hline Missing data $(\mathrm{N}, \%)$ & $2(3.85)$ & $2(7.14)$ & 0 & \\
\hline Difficulty (M, SD) & $63.96(22.88)$ & $65.31(23.42)$ & $62.50(22.70)$ & $W=335, p=0.66$ \\
\hline Missing data (N, \%) & $2(3.85)$ & $2(7.14)$ & 0 & \\
\hline Stress (M, SD) & $50.16(27.09)$ & $52.81(24.61)$ & $47.29(29.82)$ & $W=345, p=0.525$ \\
\hline Missing data $(\mathrm{N}, \%)$ & $2(3.85)$ & $2(7.14)$ & 0 & \\
\hline Controllability (M, SD) & $49.12(29.19)$ & $54.04(33.32)$ & $43.79(23.48)$ & $W=376, p=0.212$ \\
\hline Missing data $(\mathrm{N}, \%)$ & $2(3.85)$ & $2(7.14)$ & 0 & \\
\hline Predictability (M, SD) & $32.73(29.23)$ & $36.88(27.22)$ & $28.00(31.36)$ & $W=303, p=0.247$ \\
\hline Missing data $(\mathrm{N}, \%)$ & $7(13.46)$ & $4(14.29)$ & $3(12.50)$ & \\
\hline
\end{tabular}

Note. LICSP = Lausanne Infant Crying Stress Paradigm. Significant group differences were tested with Mann-Whitney (W) or chi-square $\left(X^{2}\right)$ tests. Characteristics of the stress phase were assessed on a 100-point Likert scale, with $0=$ not at all, $50=$ moderately, $100=$ extremely.

\subsection{ANS Response to Psychosocial Stress}

ANS properties during the LICSP, including HF power, LF power, and LF/HF ratio, are displayed in Table 3. A significant time effect was observed for HF power $(F(3 ; 142.47)=4.59, p=0.006)$ (Figure 2$)$, with a significant increase in HF power from the baseline (i.e., HF1) to the cognitive stressor (i.e., HF3) $(p=0.004, d=0.21)$, followed by a HF power decrease during the recovery (i.e., HF4) $(p=0.066, d=-0.20)$. A moderate group effect was found for HF power when controlling for the perceived life threat for the infant $(F(1 ; 197)=3.32, p=0.07, d=-0.53)$. Mothers at risk of CB-PTSD showed higher adjusted mean of HF power $(M=508.01, S D=351.36)$ than women at low risk $(M=287.79$, $S D=469.47$.

Regarding LF power, a significant time effect was observed $(F(3 ; 143.26)=14.39$, $p<0.001$ ) (Figure 2). From the baseline (i.e., LF1) to the cognitive stressor (i.e., LF3), LF power significantly increased $(p<0.001, d=0.77)$ before significantly decreasing during the recovery (i.e., LF4) $(p<0.001, d=-0.78)$, showing medium to large effect sizes. No significant group effect on mean LF power was detected, even when adjusting for the perceived life threat for the infant.

There was a mean LF/HF ratio time effect $(F(3 ; 143.47)=10.42, p<0.001)$ (Figure 2) with a decrease between baseline (LF/HF1) and the psychosocial stressor (i.e., LF/HF2, $p=0.002, d=-0.29$ ) and an increase to the cognitive stressor (i.e., LF/HF3, $p<0.001$, $d=0.54$ ). The group effect for the mean LF/HF ratio was large and was only significant when controlling for the perceived life threat for the infant $(F(1,197)=10.84, p<0.001$, $d=0.93)$, with mothers of the high-risk condition showing a lower adjusted mean LF/HF ratio $(\mathrm{M}=1.59, \mathrm{SD}=2.16)$ than the ones of the low-risk group $(M=3.95, S D=2.83)$. 

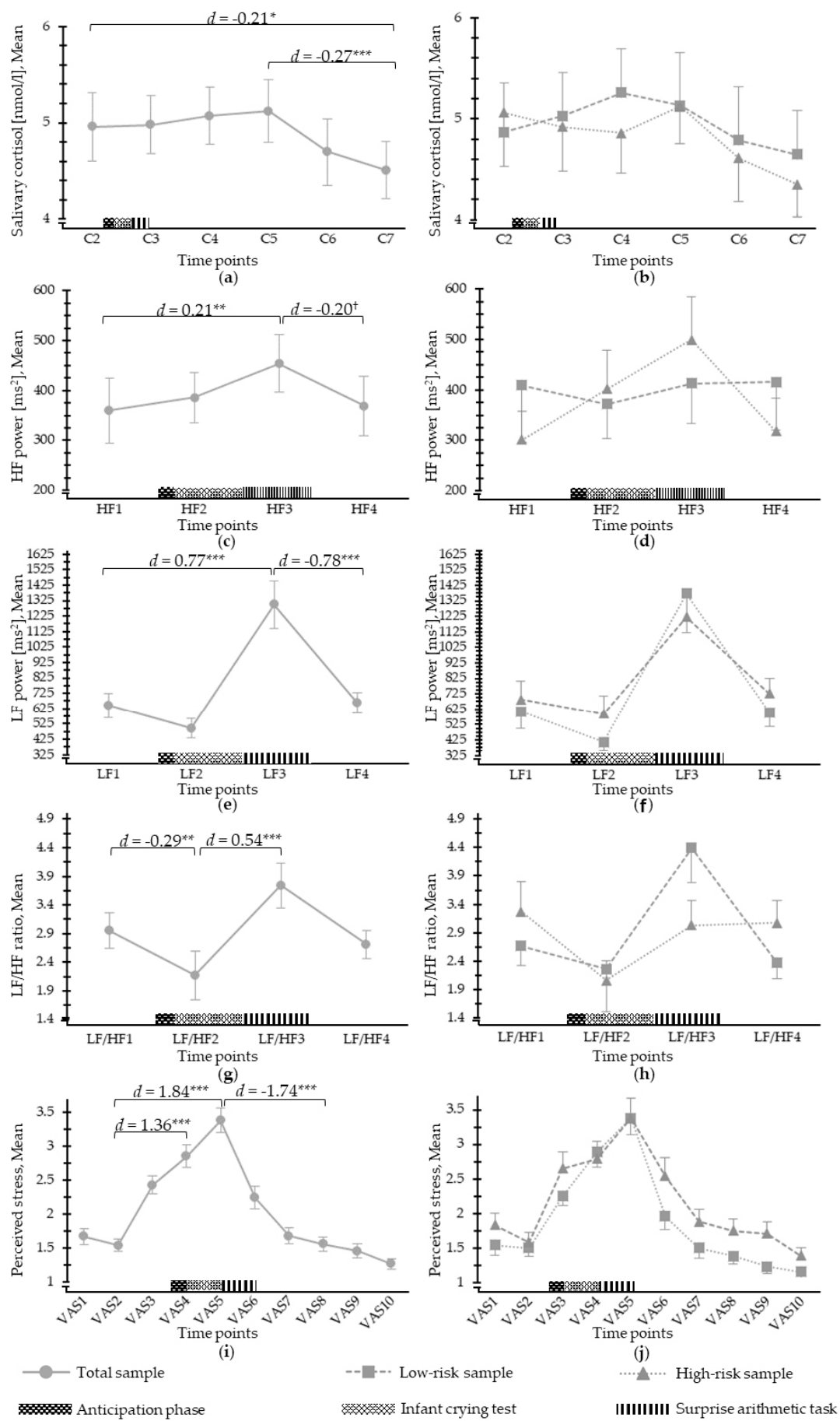

Figure 2. Mean psychophysiological stress reactivity during the different phases of the Lausanne Infant Crying Stress Paradigm: (a) mean salivary cortisol for the total sample; (b) mean salivary cortisol for the low- and high-risk groups; (c) mean HF power (HF, range: $0.15-0.4 \mathrm{~ms}^{2}$ ) for the total sample; (d) mean HF power for the low- and high-risk groups; (e) mean LF power (LF, range: $0.04-0.15 \mathrm{~ms}^{2}$ ) for the total sample; (f) mean LF power for the low- and high-risk groups; (g) mean LF/HF ratio for the total sample; (h) mean LF/HF ratio for the low- and high-risk groups; (i) mean perceived stress ratings (range: $1=$ not at all to 5 = extremely) for the total sample; (j) mean perceived stress for the low- and high-risk groups. Error bars represent standard error. Graphs showing mean group stress response patterns over time are unadjusted and are displayed for illustrative purposes. When controlling for the perceived infant life threat, significant or marginal group effects on salivary cortisol release $\left(d=0.53^{*}\right)$, HF power $\left(d=0.53^{\dagger}\right)$, LF/HF ratio $\left(d=0.93^{* * *}\right)$, and perceived stress $\left(d=0.91^{* * *}\right)$ emerged that are not indicated in this figure. ${ }^{\dagger} p<0.10,{ }^{*} p<0.05,{ }^{* *} p<0.01,{ }^{* * *} p<0.001$. 


\subsection{Perceived Stress in Response to Psychosocial Stress}

A significant time effect was reported for perceived stress $(F(9 ; 450)=43.10, p<0.001)$ (Figure 2). Perceived stress from the baseline, i.e., VAS2, increased during the psychosocial and cognitive stressors (VAS4: $p<0.001, d=1.36$; VAS5: $p<0.001, d=1.84$ ) and then decreased during recovery, i.e., VAS8 $(p<0.001, d=-1.79)$. The group effect was large and significant when controlling for the perceived life threat for the infant $(F(1,517)=25.89, p<0.001, d=0.91)$, but not otherwise. Hence, high-risk mothers reported more perceived stress $\left(M_{\text {adjusted }}=2.55, S D_{\text {adjusted }}=1.17\right)$ than low-risk mothers during the $\operatorname{LICSP}\left(M_{\text {adjusted }}=1.53, S D_{\text {adjusted }}=1.07\right)$.

\section{Discussion}

Changes in psychophysiological stress responses occurring during the early postpartum period after traumatic childbirth have not been investigated so far. However, these changes might play a significant role in the development of CB-PTSD. In this study, the first evidence for the validation of a new stress paradigm, namely the LICSP, was collected regarding the ANS and subjective stress responses of mothers in the early postpartum period (2-3 days after childbirth).

Results revealed that the LICSP elicits ANS and subjective stress responses in women in the early postpartum period. Mothers perceived increased levels of stress and an increase in LF power, which corresponds with primary SNS activation as a response to the stress task. In parallel, HF power representing PNS activation also increased during the stress task, which did not correspond with our expectations. Further, salivary cortisol did not change in response to the stress task, but it maintained an increased level that already existed before the stress induction up to the expected peak time point in response to the stress task and declined afterward, showing significantly lower levels at the end of the paradigm than at baseline.

Further, the results of this study revealed higher perceived stress, higher HF power, and lower LF/HF ratio in the high-risk group when controlling for the role of the perceived life threat for the infant, with moderate to large effect sizes. Although these results need to be replicated, these group differences hint at future possibilities of identifying distinct early stress responses in mothers at high risk of developing CB-PTSD, with important implications for the early identification of those potentially in need of professional support.

In sum, the LICSP revealed stress responses to the new paradigm in the total sample of postpartum mothers. There was no increase in salivary cortisol in response to the LICSP, as mothers showed increased levels of cortisol already at baseline. Reasons for this could be diverse but are likely to be linked to the anticipation of participating in a study. First, mothers were instructed to breastfeed and have lunch before the start of the LICSP at 1 p.m. Managing these requirements, as well as the demands related to the early postpartum period (e.g., maternal and newborn care, hospital schedule for lunch) might have been a source of stress, augmenting the mean baseline salivary cortisol level. In addition, given that mothers knew they would be separated from their infant during the upcoming stress phase, they might have been more stressed by anticipating this moment. Therefore, assessment after the anticipation period (C2) showed lower cortisol levels than during the baseline (C1), and the cortisol levels remained higher than expected until after the expected peak in relation to the stress task. Potentially, an appropriate salivary cortisol baseline could have been obtained by prolonging the baseline period.

Overall, the mean cortisol levels observed in the current sample were higher than what was previously observed in traumatized vs. nontraumatized women [38]. In the early postpartum period, various confounders might have influenced HPA activation, including sleep deprivation and parenting challenges after birth [45,66-68]. Regarding the cortisol reactivity, estrogen, progesterone, oxytocin, and prolactin are known to play a major role in the initiation and maintaining of lactation and might blunt or reduce HPA activation during a stress task $[69,70]$. A study reported diminished blood cortisol reactivity in lactating women at 2 months postpartum [71]. In contrast, cortisol levels in our sample 
were increased. This discrepancy could be the result of the fact that assessment took place only a few days after childbirth when the lactation was only initiated, which is a different stage of the postpartum period and therefore difficult to compare. Further, cortisol levels could have been affected by hormonal conditions related to the previous pregnancy state, but there is evidence showing that maternal salivary cortisol should return to prepregnancy levels at 12-24 $\mathrm{h}$ postpartum [31,32].

Another reason for these results could be that the overall level of stress during the stress phase may not have been sufficiently intense to further activate the HPA axis [29]. The limited social-evaluative threat (i.e., when some part of the self is judged by others) might have caused less HPA activation during the LICSP [46], as, contrary to the stress phase of the TSST that contains a panel of experimenters [47], the stress phase of the LICSP includes only one experimenter. Therefore, the single experimenter might have had less of a social-evaluative impact, thus limiting the cortisol release. Further, the absence of face-to-face feedback from the experimenter on the participant's performance during the ICT may have decreased the social-evaluative threat [72].

The results clearly showed an increase in perceived stress and LF power, a marker for SNS activation under stress, and an unexpected parallel increase in HF power. This is contrary to a previous study with pregnant women revealing HF power withdrawal, a decreased LF/HF ratio, but no change in LF power [42]. Given that following childbirth, the HPA activation changes back to nonpregnant stages, similar returns to a nonpregnant stage of ANS activation could have been expected [30,31,73]. However, an examination of the HF response pattern revealed an increase in HF power in the total sample and particularly in the high-risk group. This could be related to the pain condition after birth caused by compensatory sympathoadrenal activation that includes catecholamine release into the circulation system [74] in the total sample, which may result in parallel activation of SNS and PNS. It does not, however, explain the difference between the high- and lowrisk groups. Interestingly, a previous study reported a similar increase in maternal PNS activation during a stress task that caused ruminations in relation to the threat of being separated from the child [73]. This coactivation of SNS and PNS in the high-risk group could be related to the levels of hypervigilance after the trauma [73] and could have caused contradictory PNS elevation during the task as mothers, while listening to infants' crying, might have had ruminations linked to their baby's wellbeing.

Moderate and large effects were found for differences between high- and low-risk groups in relation to other physiological stress responses. We, therefore, conclude that when controlling for the infant life threat, mothers at high risk of CB-PTSD report more perceived stress and show altered ANS and HPA activation during a stress task within the first days after childbirth. Psychophysiological stress mechanisms potentially involved in CB-PTSD development seem to be differently affected according to whether a danger was perceived for the mother or the infant during childbirth. This is not surprising given that admission to neonatal intensive care is a predictor of CB-PTSD [75]. This assumption is supported by recent evidence showing that PTSD and CB-PTSD differ in symptomatology [19,75-77]. Reassessment after a couple of weeks might reveal a different stress response pattern, particularly regarding the HPA response.

\subsection{Strengths and Limitations}

This study addresses a methodological gap in perinatal stress research. To our knowledge, this is the first study that examined physiological stress reactivity in mothers who recently gave birth using a stress paradigm, which allows assessment in a hospital ward context. The development of the LICSP was based on the gold standard of lab-based stress testing, the TSST, which is a robust stress paradigm [46,47]. The sample of this study included mothers at risk of CB-PTSD with lower parity and more operative vaginal deliveries and emergency cesarian sections, which are known to be risk factors for CBPTSD [13,14,17], thus suggesting a good internal validity. The fact that the measurement of stress responses included psychological and physiological responses, namely both stress 
branches (HPA axis and ANS), and the application of a standardized procedure (LICSP) are strengths of the study. The manipulation check of the LICSP (Table 2) further revealed that high novelty, high difficulty, and low predictability but medium controllability were achieved.

Nonetheless, some limitations must be highlighted. First, the mean salivary cortisol level at baseline (C1) was higher than expected for a baseline [78]. Future research could address this by lengthening the baseline, although the circumstances in this early postpartum period might not allow this to be feasible. Second, early postpartum factors might have influenced stress responses and would need to be assessed in the future (e.g., oxytocin provoking a blunted HPA response) [69-71]. Third, sleep deprivation [66-68] or lifestyle factors (e.g., history of nicotine, alcohol, or caffeine use) [45] could have caused physiological changes, none of which were included here as covariates, given the small sample size. Fourth, potential PTSD symptoms resulting from previous traumatic events were not assessed, which could have impacted the wellbeing of postpartum mothers $[35,36]$. Fifth, this study would have benefitted from the inclusion of a passive control group. Sixth, seven participants stopped the surprise mental arithmetic task before entirely completing it, leading to missing HRV data. To our knowledge, previous studies did not report such details. Consequently, we cannot compare whether this early stress phase termination is higher in our sample than in other populations. Finally, although the screening questions were based on PTSD stressor criteria of DSM- 5 and previously used [1,18,48,63], assessing CB-PTSD risk with only these two items is an important limitation, and validated assessment of CB-PTSD risk should be developed to be considered in future studies.

\subsection{Future Research Perspectives}

The literature suggests that an altered stress activity might play a major role in the development of PTSD and, by extension, CB-PTSD [4,5]. In our study, high-risk mothers perceived higher stress levels and showed altered ANS and HPA activation during the LICSP stress paradigm, when controlling for the perceived infant life threat. Given that important research gaps persist, further studies need to be conducted to better understand these psychological and physiological stress mechanisms at such an early time period after giving birth and how these are linked to the development of CB-PTSD later on. The findings of this study need replication in a larger sample, and the LICSP procedure would benefit from further adaptations, including changing the conditions for the baseline assessment and improving the psychosocial stressor of the LICSP in order to elicit more intense physiological stress responses. Adding a passive control group is needed to better understand the LICSP's potential in eliciting physiological stress responses. Regarding the utility of the LICSP to identify biomarkers specific to CB-PTSD, longitudinal studies need to be conducted, with CB-PTSD assessment at least one month following childbirth.

Author Contributions: Conceptualization, A.H., V.S., N.M.-B., S.S., and C.D.; methodology, A.H., V.S., N.M.-B., S.S., and C.D.; software, V.S., A.L., N.M.-B., and M.R.; validation, V.S. and A.H.; formal analysis, A.L., and V.S.; investigation, V.S., M.Q.D., and C.D.; resources, A.H., N.M.-B., and U.E.; data curation, A.L., V.S., and A.H.; writing-original draft preparation, V.S., A.H., and M.Q.D.; writing-review and editing, V.S., A.H., and N.M.-B.; visualization, V.S., A.H., and A.L.; supervision, A.H., and N.M.-B.; project administration, V.S., M.Q.D., and A.H.; funding acquisition, A.H. All authors have read and agreed to the published version of the manuscript.

Funding: This research was funded by a project grant to A.H. from the Swiss National Science Foundation (SNF 32003B_172982/1). A.H. is a management committee member of COST action CA18211.

Institutional Review Board Statement: The study was conducted according to the guidelines of the Declaration of Helsinki, and approved by Cantonal Ethics Committee of Vaud (study number 2017-02142, approved on 5 March 2018).

Informed Consent Statement: Informed consent was obtained from all subjects involved in the study. 
Data Availability Statement: The data presented in this study are available on request from the corresponding author. The data are not publicly available due to the lack of informed consent from participants for open access publication of their data.

Acknowledgments: The authors thank Lara-Jessica Schütz, Leah Gilbert, Anna Favero, Mathilde Duroux, Yasmina Lofti, Mélanie Hausser, Annabelle Reuse, Ava Cepleanu, Cassie Pernet, Daniela Barros Rodriguez, and Camille Palombo for their precious help with data collection. The authors are grateful to Sandrine Estoppey Younes, Jardena Puder, and David Baud for their logistical support and the START Research Consortium (see Sandoz et al., 2019 for a full listing). Finally, our sincere thanks are addressed to the staff of the postpartum unit.

Conflicts of Interest: The authors declare no conflict of interest.

\section{References}

1. American Psychiatric Association. Diagnostic and Statistical Manual of Mental Disorders, 5th ed.; American Psychiatric Publishing: Arlington, VA, USA, 2013.

2. Olde, E.; van der Hart, O.; Kleber, R.; van Son, M. Posttraumatic stress following childbirth: A review. Clin. Psychol. Rev. 2006, 26, 1-16. [CrossRef]

3. King, L.; McKenzie-McHarg, K.; Horsch, A. Testing a cognitive model to predict posttraumatic stress disorder following childbirth BMC Pregnancy Childbirth 2017, 17, 32. [CrossRef]

4. Ehlert, U.; Gaab, J.; Heinrichs, M. Psychoneuroendocrinological contributions to the etiology of depression, posttraumatic stress disorder, and stress-related bodily disorders: The role of the hypothalamus-pituitary-adrenal axis. Biol. Psychol. 2001, 57, 141-152. [CrossRef]

5. Nagpal, M.; Gleichauf, K.; Ginsberg, J. Meta-analysis of heart rate variability as a psychophysiological indicator of posttraumatic stress disorder. Trauma Treat. 2013, 3. [CrossRef]

6. Soet, J.E.; Brack, G.A.; Dilorio, C. Prevalence and predictors of women's experience of psychological trauma during childbirth Birth 2003, 30, 36-46. [CrossRef]

7. Ayers, S. Delivery as a traumatic event: Prevalence, risk factors, and treatment for postnatal posttraumatic stress disorder. Clin. Obstet. Gynecol. 2004, 47, 552-567. [CrossRef]

8. Slade, P. Towards a conceptual framework for understanding post-traumatic stress symptoms following childbirth and implications for further research. J. Psychosom. Obstet. Gynecol. 2006, 27, 99-105. [CrossRef] [PubMed]

9. Horsch, A.; Garthus-Niegel, S. Posttraumatic stress disorder following childbirth. In Childbirth, Vulnerability and Law: Exploring Issues of Violence and Control, 1st ed.; Herring, C.P.J., Ed.; Routledge: London, UK, 2019; pp. 49-66.

10. Zaers, S.; Waschke, M.; Ehlert, U. Depressive symptoms and symptoms of post-traumatic stress disorder in women after childbirth. J. Psychosom. Obstet. Gynecol. 2008, 29, 61-71. [CrossRef] [PubMed]

11. Ayers, S.; Bond, R.; Bertullies, S.; Wijma, K. The aetiology of post-traumatic stress following childbirth: A meta-analysis and theoretical framework. Psychol. Med. 2016, 46, 1121-1134. [CrossRef] [PubMed]

12. Grekin, R.; O’Hara, M.W. Prevalence and risk factors of postpartum posttraumatic stress disorder: A meta-analysis. Clin. Psychol. Rev. 2014, 34, 389-401. [CrossRef] [PubMed]

13. Dikmen-Yildiz, P.; Ayers, S.; Phillips, L. The prevalence of posttraumatic stress disorder in pregnancy and after birth: A systematic review and meta-analysis. J. Affect. Disord. 2017, 208, 634-647. [CrossRef]

14. Ayers, S.; Harris, R.; Sawyer, A.; Parfitt, Y.; Ford, E. Posttraumatic stress disorder after childbirth: Analysis of symptom presentation and sampling. J. Affect. Disord. 2009, 119, 200-204. [CrossRef]

15. Soderquist, J.; Wijma, K.; Wijma, B. Traumatic Stress after Childbirth: The Role of Obstetric Variables. J. Psychosom. Obstet. Gynecol. 2002, 23, 31-39. [CrossRef] [PubMed]

16. van Heumen, M.A.; Hollander, M.H.; van Pampus, M.G.; van Dillen, J.; Stramrood, C.A.I. Psychosocial Predictors of Postpartum Posttraumatic Stress Disorder in Women With a Traumatic Childbirth Experience. Front. Psychiatry 2018, 9. [CrossRef] [PubMed]

17. Andersen, L.B.; Melvaer, L.B.; Videbech, P.; Lamont, R.F.; Joergensen, J.S. Risk factors for developing post-traumatic stress disorder following childbirth: A systematic review. Acta Obstet. Gynecol. Scand. 2012, 91, 1261-1272. [CrossRef] [PubMed]

18. Sandoz, V.; Deforges, C.; Stuijfzand, S.; Epiney, M.; Vial, Y.; Sekarski, N.; Messerli-Bürgy, N.; Ehlert, U.; Bickle-Graz, M.; Morisod Harari, M.; et al. Improving mental health and physiological stress responses in mothers following traumatic childbirth and in their infants: Study protocol for the Swiss TrAumatic biRth Trial (START). BMJ Open 2019, 9, e032469. [CrossRef]

19. Horesh, D.; Garthus-Niegel, S.; Horsch, A. Childbirth-related PTSD: Is it a unique post-traumatic disorder? J. Reprod. Infant Psychol. 2021, 39, 221-224. [CrossRef]

20. Garthus-Niegel, S.; Horsch, A.; Handtke, E.; von Soest, T.; Ayers, S.; Weidner, K.; Eberhard-Gran, M. The impact of postpartum posttraumatic stress and depression symptoms on couples' relationship satisfaction: A population-based prospective study. Front. Psychol. 2018, 9, 1728. [CrossRef]

21. Delicate, A.; Ayers, S.; Easter, A.; McMullen, S. The impact of childbirth-related post-traumatic stress on a couple's relationship: A systematic review and meta-synthesis. J. Reprod. Infant Psychol. 2018, 36, 102-115. [CrossRef] 
22. Cook, N.; Ayers, S.; Horsch, A. Maternal posttraumatic stress disorder during the perinatal period and child outcomes: A systematic review. J. Affect. Disord. 2018, 225, 18-31. [CrossRef] [PubMed]

23. Garthus-Niegel, S.; Horsch, A.; von Soest, T.; Haga, S.M.; Drozd, F.; Ayers, S.; Eberhard-Gran, M. Posttraumatic stress symptoms following childbirth: Associations with prenatal attachment in subsequent pregnancies. Arch. Women's Ment. Health 2019, 23, 547-555. [CrossRef] [PubMed]

24. Garthus-Niegel, S.; Ayers, S.; Martini, J.; Von Soest, T.; Eberhard-Gran, M. The impact of postpartum post-traumatic stress disorder symptoms on child development: A population-based, 2-year follow-up study. Psychol. Med. 2017, 47, 161-170. [CrossRef] [PubMed]

25. Garthus-Niegel, S.; Horsch, A.; Ayers, S.; Junge-Hoffmeister, J.; Weidner, K.; Eberhard-Gran, M. The influence of postpartum PTSD on breastfeeding: A longitudinal population-based study. Birth 2018, 45, 193-201. [CrossRef] [PubMed]

26. Stuijfzand, S.; Garthus-Niegel, S.; Horsch, A. Parental birth-related PTSD symptoms and bonding in the early postpartum period: A prospective population-based cohort study. Front. Psychiatry 2020, 11. [CrossRef]

27. Bastos, M.H.; Furuta, M.; Small, R.; McKenzie-McHarg, K.; Bick, D. Debriefing interventions for the prevention of psychological trauma in women following childbirth. Cochrane Database Syst. Rev. 2015, CD007194. [CrossRef] [PubMed]

28. Horsch, A. Post traumatic stress disorder following childbirth and pregnancy loss. In Clinical Psychology in Practice; Beinard, H., Kennedy, P.S.L., Eds.; Blackwell, BPS: Oxford, UK, 2009; pp. 274-287.

29. Del Giudice, M.; Ellis, B.J.; Shirtcliff, E.A. The Adaptive Calibration Model of stress responsivity. Neurosci. Biobehav. Rev. 2011, 35, 1562-1592. [CrossRef] [PubMed]

30. Benfield, R.D.; Newton, E.R.; Tanner, C.J.; Heitkemper, M.M. Cortisol as a biomarker of stress in term human labor: Physiological and methodological issues. Biol. Res. Nurs. 2014, 16, 64-71. [CrossRef]

31. Falk-Smith, N.L.; Madrigal, L. Maternal stress, anxiety, and fear of childbirth among planned homebirth mothers: Results from a mixed methods study. In Proceedings of the 88th Annual Meeting of the American Association of Physical Anthropologists, Cleveland, OH, USA, 27 March 2019; pp. 71-72.

32. Miller, N.; Asali, A.A.; Agassi-Zaitler, M.; Neumark, E.; Eisenberg, M.M.; Hadi, E.; Elbaz, M.; Pasternak, Y.; Fishman, A.; Biron-Shental, T. Physiological and psychological stress responses to labor and delivery as expressed by salivary cortisol: A prospective study. Am. J. Obstet. Gynecol. 2019, 221, 351.e351-e357. [CrossRef]

33. Meulenberg, P.M.; Hofman, J.A. Differences between concentrations of salivary cortisol and cortisone and of free cortisol and cortisone in plasma during pregnancy and postpartum. Clin. Chem. 1990, 36, 70-75. [CrossRef]

34. Heinrichs, M.; Neumann, I.; Ehlert, U. Lactation and stress: Protective effects of breast-feeding in humans. Stress 2002, 5, 195-203. [CrossRef]

35. Pitman, R.K.; Rasmusson, A.M.; Koenen, K.C.; Shin, L.M.; Orr, S.P.; Gilbertson, M.W.; Milad, M.R.; Liberzon, I. Biological studies of post-traumatic stress disorder. Nat. Rev. Neurosci. 2012, 13, 769-787. [CrossRef] [PubMed]

36. Miller, G.E.; Chen, E.; Zhou, E.S. If it goes up, must it come down? Chronic stress and the hypothalamic-pituitary-adrenocortical axis in humans. Psychol. Bull. 2007, 133, 25-45. [CrossRef]

37. England-Mason, G.; Kimber, M.; Khoury, J.; Atkinson, L.; MacMillan, H.; Gonzalez, A. Difficulties with emotion regulation moderate the association between childhood history of maltreatment and cortisol reactivity to psychosocial challenge in postpartum women. Horm. Behav. 2017, 95, 44-56. [CrossRef] [PubMed]

38. Pierce, M.E.; Pritchard, L.M. Lower stress-reactive cortisol in female veterans associated with military status but not PTSD. Stress 2016, 19, 486-491. [CrossRef] [PubMed]

39. Elzinga, B.M.; Schmahl, C.G.; Vermetten, E.; Van Dyck, R.; Bremner, J.D. Higher cortisol levels following exposure to traumatic reminders in abuse-related PTSD. Neuropsychopharmacology 2003, 28, 1656-1665. [CrossRef] [PubMed]

40. Cordero, M.I.; Moser, D.A.; Manini, A.; Suardi, F.; Sancho-Rossignol, A.; Torrisi, R.; Rossier, M.F.; Ansermet, F.; Dayer, A.G.; Rusconi-Serpa, S.; et al. Effects of interpersonal violence-related post-traumatic stress disorder (PTSD) on mother and child diurnal cortisol rhythm and cortisol reactivity to a laboratory stressor involving separation. Horm. Behav. 2017, 90, 15-24. [CrossRef]

41. Shaffer, F.; McCraty, R.; Zerr, C.L. A healthy heart is not a metronome: An integrative review of the heart's anatomy and heart rate variability. Front. Psychol. 2014, 5. [CrossRef]

42. Klinkenberg, A.V.; Nater, U.M.; Nierop, A.; Bratsikas, A.; Zimmermann, R.; Ehlert, U. Heart rate variability changes in pregnant and non-pregnant women during standardized psychosocial stress 1. Acta Obstet. Gynecol. Scand. 2009, 88, 77-82. [CrossRef]

43. Shaffer, F.; Ginsberg, J.P. An overview of heart rate variability metrics and norms. Front. Public Health 2017, 5, 258. [CrossRef]

44. Finan, P.H.; Zautra, A.J.; Wershba, R. The dynamics of emotions in adaptation to stress. In The Handbook of Stress Science: Biology, Psychology, and Health; Contrada, R.J., Baum, A., Eds.; Springer Publishing Company: New York, NY, USA, 2011 ; pp. $209-220$. [CrossRef]

45. Kudielka, B.M.; Hellhammer, D.H.; Kirschbaum, C. Ten years of research with the Trier Social Stress Test-revisited. In Social Neuroscience: Integrating Biological and Psychological Explanations of Social Behavior; Winkielman, E.H.-J.P., Ed.; The Guilford Press: New York, NY, USA, 2007; pp. 56-83. [CrossRef]

46. Dickerson, S.S.; Kemeny, M.E. Acute stressors and cortisol responses: A theoretical integration and synthesis of laboratory research. Psychol. Bull. 2004, 130, 355-391. [CrossRef] 
47. Kirschbaum, C.; Pirke, K.-M.; Hellhammer, D.H. The 'Trier Social Stress Test'-a tool for investigating psychobiological stress responses in a laboratory setting. Neuropsychobiology 1993, 28, 76-81. [CrossRef] [PubMed]

48. Ayers, S.; Crawley, R.; Webb, R.; Button, S.; Thornton, A.; the HABiT collaborative group. What are women stressed about after birth? Birth 2019, 46, 678-685. [CrossRef]

49. Von Elm, E.; Altman, D.G.; Egger, M.; Pocock, S.J.; Gøtzsche, P.C.; Vandenbroucke, J.P. The Strengthening the Reporting of Observational Studies in Epidemiology (STROBE) statement: Guidelines for reporting observational studies. Ann. Intern. Med. 2007, 147, 573-577. [CrossRef]

50. Meyer, T.; Albrecht, J.; Bornschein, G.; Sachsse, U.; Herrmann-Lingen, C. Posttraumatic Stress Disorder (PTSD) patients exhibit a blunted parasympathetic response to an emotional stressor. Appl. Psychophysiol. Biofeedback 2016, 41, 395-404. [CrossRef]

51. Bouchet, H.; Plat, A.; Levréro, F.; Reby, D.; Patural, H.; Mathevon, N. Baby cry recognition is independent of motherhood but improved by experience and exposure. Proc. R. Soc. B Biol. Sci. 2020, 287, 20192499. [CrossRef]

52. Bozovic, D.; Racic, M.; Ivkovic, N. Salivary cortisol levels as a biological marker of stress reaction. Med. Arch. 2013, 67, 374-377. [CrossRef]

53. Hellhammer, D.H.; Wust, S.; Kudielka, B.M. Salivary cortisol as a biomarker in stress research. Psychoneuroendocrinology 2009, 34, 163-171. [CrossRef]

54. Messerli-Bürgy, N.; Kakebeeke, T.H.; Arhab, A.; Stülb, K.; Zysset, A.E.; Leeger-Aschmann, C.S.; Schmutz, E.A.; Fares, F.; Meyer, A.H.; Munsch, S.; et al. The Swiss Preschoolers' health study (SPLASHY): Objectives and design of a prospective multi-site cohort study assessing psychological and physiological health in young children. BMC Pediatrics 2016, 16, 1-16. [CrossRef] [PubMed]

55. Schobinger, E.; Stuijfzand, S.; Horsch, A. Acute and post-traumatic stress disorder symptoms in mothers and fathers following childbirth: A prospective cohort study. Front. Psychiatry 2020, 11. [CrossRef]

56. Cox, J.L.; Holden, J.M.; Sagovsky, R. Detection of postnatal depression. Development of the 10-item Edinburgh Postnatal Depression Scale. Br. J. Psychiatry 1987, 150, 782-786. [CrossRef] [PubMed]

57. Guedeney, N.; Fermanian, J. Validation study of the French version of the Edinburgh Postnatal Depression Scale (EPDS): New results about use and psychometric properties. Eur. Psychiatry 1998, 13, 83-89. [CrossRef]

58. Horsch, A.; Tolsa, J.-F.; Gilbert, L.; Jan Du Chêne, L.; Müller-Nix, C.; Bickle-Graz, M. Improving maternal mental health following preterm birth using an expressive writing intervention: A randomized controlled trial. Child Psychiatry Human Dev. 2016, 47, 780-791. [CrossRef]

59. Sandoz, V.; Bickle-Graz, M.; Camos, V.; Horsch, A. Maternal postpartum depression symptoms are negatively associated with emotion regulation of children born very preterm. Acta Paediatr. 2019, 108, 969-970. [CrossRef] [PubMed]

60. Zigmond, A.S.; Snaith, R.P. The Hospital Anxiety and Depression Scale. Acta Psychiatr. Scand. 1983, 67, 361-370. [CrossRef]

61. Bocéréan, C.; Dupret, E. A validation study of the Hospital Anxiety and Depression Scale (HADS) in a large sample of French employees. BMC Psychiatry 2014, 14. [CrossRef]

62. Horsch, A.; Vial, Y.; Favrod, C.; Morisod Harari, M.; Blackwell, S.E.; Watson, P.; Iyadurai, L.; Bonsall, M.B.; Holmes, E.A. Reducing intrusive traumatic memories after emergency caesarean section: A proof-of-principle randomized controlled study. Behav. Res. Ther. 2017, 94, 36-47. [CrossRef] [PubMed]

63. Mason, J.W. A review of psychoendocrine research on the pituitary-adrenal cortical system. Psychosom. Med. 1968, 30, 576-607. [CrossRef]

64. R Development Core Team. R: A Language and Environment for Statistical Computing; R Foundation for Statistical Computing: Vienna, Austria, 2019.

65. Van Buuren, S.; Groothuis-Oudshoorn, K. MICE: Multivariate Imputation by Chained Equations in R. J. Stat. Softw. 2011, 45, 1-68. [CrossRef]

66. Heinrichs, M.; Baumgartner, T.; Kirschbaum, C.; Ehlert, U. Social support and oxytocin interact to suppress cortisol and subjective responses to psychosocial stress. Biol. Psychiatry 2003, 54, 1389-1398. [CrossRef]

67. Wright, K.P.; Drake, A.L.; Frey, D.J.; Fleshner, M.; Desouza, C.A.; Gronfier, C.; Czeisler, C.A. Influence of sleep deprivation and circadian misalignment on cortisol, inflammatory markers, and cytokine balance. Brain Behav. Immun. 2015, 47, 24-34. [CrossRef]

68. Almanza-Sepulveda, M.L.; Fleming, A.S.; Jonas, W. Mothering revisited: A role for cortisol? Horm. Behav. 2020, 121, 104679. [CrossRef] [PubMed]

69. Lawrence, R.A.; Lawrence, R.M. Physiology of lactation. In Breastfeeding, 7th ed.; Lawrence, R.A., Lawrence, R.M., Eds.; W.B. Saunders: Philadelphia, PA, USA, 2011; pp. 62-97.

70. Kaye, J.; Soothill, P.; Hunt, M.; Lightman, S. Responses to the 35\% CO challenge in postpartum women. Clin. Endocrinol. 2004, 61, 582-588. [CrossRef] [PubMed]

71. Bauer, A.E.; Wouk, K.; Grewen, K.; Gottfredson, N.C.; Meltzer-Brody, S.; Propper, C.; Mills-Koonce, R.; Pearson, B.; Whitley, J.; Stuebe, A.M. Associations of postpartum depression symptoms and infant feeding with Hypothalamic Pituitary Adrenal (HPA) axis reactivity. Am. J. Obstet. Gynecol. 2020, 222, S114. [CrossRef]

72. Giles, G.E.; Mahoney, C.R.; Brunyé, T.T.; Taylor, H.A.; Kanarek, R.B. Stress effects on mood, HPA axis, and autonomic response: Comparison of three psychosocial stress paradigms. PLoS ONE 2014, 9, e113618. [CrossRef] [PubMed]

73. Schechter, D.S.; Moser, D.A.; McCaw, J.E.; Myers, M.M. Autonomic functioning in mothers with interpersonal violence-related posttraumatic stress disorder in response to separation-reunion. Dev. Psychobiol. 2014, 56, 748-760. [CrossRef] [PubMed] 
74. Terkelsen, A.J.; Mølgaard, H.; Hansen, J.; Andersen, O.K.; Jensen, T.S. Acute pain increases heart rate: Differential mechanisms during rest and mental stress. Auton. Neurosci. 2005, 121, 101-109. [CrossRef]

75. Harrison, S.E.; Ayers, S.; Quigley, M.A.; Stein, A.; Alderdice, F. Prevalence and factors associated with postpartum posttraumatic stress in a population-based maternity survey in England. J. Affect. Disord. 2020. [CrossRef]

76. Ayers, S.; Wright, D.B.; Thornton, A. Development of a measure of postpartum PTSD: The City Birth Trauma Scale. Front. Psychiatry 2018, 9, 409. [CrossRef]

77. Sandoz, V.; Hingray, C.; Stuijfzand, S.; Lacroix, A.; El Hage, W.; Horsch, A. Measurement and conceptualization of maternal PTSD following childbirth: Psychometric properties of the City Birth Trauma Scale-French version (City BiTS-F). Psychol. Trauma 2021, 12, 147-155. [CrossRef]

78. Pruessner, J.C.; Kirschbaum, C.; Meinlschmid, G.; Hellhammer, D.H. Two formulas for computation of the area under the curve represent measures of total hormone concentration versus time-dependent change. Psychoneuroendocrinology 2003, $28,916-931$. [CrossRef] 